\title{
Effect of Dietary Probiotic Supplementation on Performance, Gut Microflora, and Hematology of Local Quails
}

\author{
Rebin A. Mirza* \\ Department of Animal Resources, College of Agricultural Engineering Sciences, Salahaddin University, Erbil, Kurdistan Region, Iraq
}

\author{
*Corresponding author: \\ Rebin A. Mirza, \\ Department of Animal \\ Resources, College of \\ Agricultural Engineering \\ Sciences, Salahaddin \\ University, Erbil, Kurdistan \\ Region, Iraq. \\ E-mail: rebin.mirza@su.edu. \\ krd
}

Received: 26 September 2019

Accepted: 10 February 2020

Published: 30 June 2020

\section{DOI}

10.25156/pti.v10n1y2020.pp93-97

\section{A B S T R A C T}

This research was conducted to evaluate the effect of probiotic supplementation on growth performance, gut microbiota, and hematology of local quails. Ninety-one-week-old quails were randomly distributed into three dietary treatments with three replicate per each for 42 days. The dietary treatments were: Treatment 1 which was control (no additive), standard diet added with Lactobacillus animalis bacteria $1 \mathrm{~g} / \mathrm{kg} 1.35 \times 10^{9}$ colony forming units (CFU)/kg (PRO1) and commercial multi-strain probiotic (Lactobacillus acidophilus $2.75 \times 10^{10} \mathrm{CFU}$, Streptococcus faecium $8.25 \times 10^{10} \mathrm{CFU}$, and Bacillus subtilis $1.1 \times 10^{10} \mathrm{CFU}$ ) (PRO2). Results showed that PRO1, isolated from chicken caeca, had probiotic properties to improve growth performance of local quail compared to the control group. In cecum digesta, addition of both types of probiotics significantly increased the number of Lactobacillus spp. and reduced the number of coliform bacteria at the end of the experiment. Furthermore, supplementation of both types of probiotics significantly increased the number of lymphocyte and reduced $\mathrm{H} / \mathrm{L}$ ratio compared to the control group at the end of the experiment. While, no significant differences were observed between both types of probiotic. This research has established that $L$. animalis, which isolated in cecum of chicken origin, had the same data recorded when compared to commercial multi-strain bacteria probiotic by improved growth performance, gut microbiota, and hematology parameters and could be a convenient probiotic additive in dietary local quail.

Keywords: Gut microbiota; Hematology; Lactobacillus; Probiotic; Quails

\section{INTRODUCTION}

The fastest-growing project of agriculture and animal husbandry sector is poultry productions. Otherwise, diet is one of the expensive items in poultry production, accounting for $70 \%$ of total poultry production. The constant increase in the cost of poultry feed ingredients and compounded feed is making less profit to poultry farmers (Kapil et al., 2015).

Today probiotics have a large and significant role in promoting the growth of broilers and increase resistance to the diseases by provide the different types of beneficial microorganisms to the diets. Therefore, one option that has the prospective to decrease the opportunity of infection of the poultry farm is the use of probiotics. There is a different definition of probiotics such as FAO/WHO defined probiotics as an alone or multi-strain bacteria added in an appropriate amount that makes a wealthy interest to the body. However, the mechanisms of action of probiotics are not completely understood. Probiotic feed supplements have been used to modulate the composition of the gut microflora by successfully competing with pathogens through a competitive exclusion process.

Several studies resulted that probiotics in broiler feed ameliorate the performance compared to non-addition probiotics into the feed to be as efficacious such antibiotic evolution provider (Kalavathy et al., 2003; Mountzouris et al., 2010; Shim et al., 2010). Some researchers resulted the influence of administration of adding a monocular strain of probiotics in broiler feed (Khosravi et al., 2010; Mountzouris et al., 2007; Zakeri and Kashefi, 2011), while others have tested two strain (Anjum et al., 2005; Mehr et al., 2007; Nayebpor et al., 2005) or multi-strain of bacteria (Mountzouris et al., 2010; Apata, 2008; Li et al., 2008; Wang and Gu, 2010). Probiotics have been used and developed for poultry is based on the information on the microbiota in the gastrointestinal tract (GIT) which is participating in the impedance to enter the harmful bacteria and stopping the growth of harmful bacteria, where it has been illustrated to be participating in safeguarding against 
a different kind of harmful bacteria including Salmonella spp., Campylobacter spp., Clostridium spp., and Escherichia coli (Jin et al., 1997; Murry et al., 2006; Ragione et al., 2004).

Most of the reported research on probiotics focuses on the use of different strains of Lactobacillus spp. While, there is no evidence that exert effect of Lactobacillus animalis on the quails. Thus, the present study was conducted to investigate the effects of $L$. animalis on performance, gut microbiota, and hematology of local quail. On the other hand, compare the L. animalis which was isolated from the cecum of chicken and commercial probiotic.

\section{MATERIALS AND METHODS}

\section{Management and Design of Experiment}

Ninety-one-day local quails were taken from a commercial farm (Erbil, Kurdistan, Iraq) and quails reared in the same place during the $1^{\text {st }}$ week before starting the experiment. Then, after 1 -week quails were randomly distributed into three treatments (30 quails per treatment) and reared in the same building. The quails were scaled and kept in nine cages $(60 \times 60 \times 40 \mathrm{~cm})$. The quails also located in a way to have full access to drinking water and feed. Each treatment had three replicates (10 quails/cage). The duration of the trial was 42 days. The dietary treatments include control diet (standard broiler diet), probiotic $1=$ control diet administrated with $1 \mathrm{~g} L$. animalis $/ \mathrm{kg}$ of feed, comprises $1 \mathrm{~g} / \mathrm{kg} 1.35 \times 10^{9}$ colony forming units (CFU)/kg (Plymouth University, United Kingdom), and probiotic $2=$ control diet with $1 \mathrm{~g} / \mathrm{kg}$ commercial multi-bacteria probiotic (L. acidophilus $2.75 \times 10^{10} \mathrm{CFU}$, Streptococcus faecium $8.25 \times 10^{10} \mathrm{CFU}$, and Bacillus subtilis 1.1 $\times 10^{10} \mathrm{CFU}$ ) with a commercial name (BIOZYME, India). Skim milk was used as a protective carrier for improving the survival ratio of $L$. animalis.

\section{Growth Performance}

All quails were weighed at the first (initial weight) and on day 42 individually after their arrival from the hatchery to the experimental farm. Final weight gain for each dietary treatment was calculated. Feed intake (FI) was recorded in the course of the whole experiment for each replicate, and the feed conversion rates (FCR) and European production efficacy factor (EPEF) were calculated subsequently.

\section{Gut Microbiota Analysis}

At the end of the experiment period, six quails were taken from treatments and their cecal digesta were fully aseptically separated to investigate the intestinal microorganisms (Lactobacillus spp. and total coliform bacteria). One hundred $\mathrm{mg}$ of each caecum digesta was mixed with $0.9 \mathrm{ml}$ of sterile PBS ( $\mathrm{pH} 7.0$ ) and vortexed for $1 \mathrm{~min}$ to homogenize. The homogenate was diluted serially from an initial $10^{-1}$ dilution to $10^{-7}$. For each dilution, $0.1 \mathrm{ml}$ from the dilution was plated onto sterile selective medium agar to count targeted bacteria groups as following; MacConkey agar (Sigma-Aldrich, UK) for total coliform and MRS agar for Lactobacillus spp. The colonies number of microbial was then counted to determine the CFU. CFU/g for fresh cecal digesta was calculated and expressed as logarithms.

\section{Hematology Parameters}

At the end of the experiment period, three quails from each treatment randomly were selected and killed by cervical dislocation. The blood samples were collected in test tubes with anticoagulant di-potassium ethylene diamine tetraacetic acid. All parameters of blood (hemoglobin, WBC, lymphocyte, heterophil, and $\mathrm{H} / \mathrm{L}$ ratio) were examined by a full-auto hematology analyzer (MCL 3800, China) (Pelicano et al., 2005; Baurhoo et al., 2007).

\section{Statistical Analysis}

The data obtained in the experiments were statistically analyzed using a one-way ANOVA test, SPSS program (Statistical Package for Social Science) (SPSS 22, 2005). Descriptive statistics aided for the analysis of the data. Therefore, means and standard error were calculated. Duncan test utilized and aided to calculate significant differences at 0.05 levels among the various parameters (Duncan, 1995).

\section{RESULTS}

The influences of probiotic administration on quality performance parameters are shown in Table 1. Insignificant

Table 1: Influence of probiotics administration on growth performance of local quails at 6 weeks of age (mean \pm standard error)

\begin{tabular}{|c|c|c|c|c|}
\hline \multirow[t]{2}{*}{ Growth performance } & \multicolumn{3}{|c|}{ Treatment } & \multirow[t]{2}{*}{$P$ value } \\
\hline & CON & PRO1 & PRO2 & \\
\hline Initial weight (g) & $24.43 \pm 0.88^{a}$ & $23.26 \pm 0.68^{a}$ & $23.18 \pm 1.08^{a}$ & 0.577 \\
\hline Final weight $(\mathrm{g})$ & $193.79 \pm 3.46^{b}$ & $211.91 \pm 4.28^{a}$ & $206.35 \pm 3.53^{a, b}$ & 0.037 \\
\hline Weight gain (g/bird) & $169.35 \pm 4.31^{\mathrm{b}}$ & $188.64 \pm 3.68^{a}$ & $183.14 \pm 4.10^{\mathrm{a}, \mathrm{b}}$ & 0.037 \\
\hline Feed intake (g/bird) & $508.62 \pm 12.73^{a}$ & $511.44 \pm 7.23^{a}$ & $508.56 \pm 8.51^{a}$ & 0.972 \\
\hline Feed convention ratio & $3.00 \pm 0.12^{\mathrm{a}}$ & $2.71 \pm 0.05^{a}$ & $2.78 \pm 0.10^{\mathrm{a}}$ & 0.190 \\
\hline EPEF$^{1}$ & $138.64 \pm 3.95^{a}$ & $136.77 \pm 1.77^{a}$ & $136.47 \pm 3.14^{\mathrm{a}}$ & 0.869 \\
\hline
\end{tabular}

${ }^{\mathrm{a}, \mathrm{b}}$ Data in the same row direction with different letters are differ significantly $(P<0.05) .{ }^{1} \mathrm{EPEF}=$ Liveability $(\%) \times$ live weight $(\mathrm{kg}) \times 100 /$ age $(\mathrm{d}) \times \mathrm{FCR}$ 
differences $(P>0.05)$ were observed between treatments on final FCR, total FI, and EPEF. While, the quails with $L$. animalis $(\mathrm{PRO} 1)$ showed a significant $(P<0.05)$ improvement in body weight and weight gain compared to other groups. While, both parameters, insignificant $(P>0.05)$ differences were observed between both types of probiotics and commercial multi probiotic (PRO2) with the control group. The best results recorded with PRO1 compared to other probiotic supplementation.

Table 2 showed the effects of $L$. animalis (PRO1) and commercial multi probiotic (PRO2) supplementation in diet on the microbiota composition in the cecum digesta of local quails at 6 weeks of age. Both types of probiotic supplementation increased significantly $(P<0.05)$, the counting of Lactobacillus spp. and reduced the number of coliform bacteria compared to control treatment. While, insignificant $(P>0.05)$ differences were observed between both types of probiotic supplementations in Lactobacillus spp. and coliform bacteria in the caeca of local quails compared to the control group.

Table 3 showed the influence of $L$. animalis (PRO1) and commercial multi probiotic (PRO2) on hematological parameters of local quails at 6 weeks of age. Both kinds of probiotics supplementation increased significantly $(P<0.05)$, the counting of WBCs compared to control treatment. Lymphocyte increased significantly $(P<0.05)$ in $L$. animalis (PRO1) compared to control treatment, while no significant $(P>0.05)$ differences were observed on lymphocyte between both kinds of probiotic supplementations and PRO2 with control treatment. Furthermore, heterophil and $\mathrm{H} / \mathrm{L}$ ratio parameters reduced

\begin{tabular}{|c|c|c|c|c|}
\hline \multirow[t]{2}{*}{ Microbes } & \multicolumn{3}{|c|}{ Treatment } & \multirow[t]{2}{*}{$P$ value } \\
\hline & CON & PR01 & PRO2 & \\
\hline Lactobacillus ssp. & $8.65 \pm 0.07^{b}$ & $9.39 \pm 0.06^{a}$ & $9.25 \pm 0.13^{a}$ & 0.005 \\
\hline Total coliform & $7.28 \pm 0.10^{\mathrm{a}}$ & $6.85 \pm 0.06^{b}$ & $6.85 \pm 0.11^{b}$ & 0.030 \\
\hline
\end{tabular}

Table 3: Influence of probiotics administration on the hematological parameters of quails at 6 weeks of age (Mean \pm SE)

\begin{tabular}{lcccc}
\hline Parameters & \multicolumn{3}{c}{ Treatment } & P value \\
\cline { 2 - 4 } & CON & PRO1 & PRO2 & \\
\hline Hemoglobin & $153.17 \pm 6.02^{\mathrm{a}}$ & $160.36 \pm 5.54^{\mathrm{a}}$ & $153.45 \pm 3.60^{\mathrm{a}}$ & 0.568 \\
WBC & $3.81 \pm 0.15^{\mathrm{b}}$ & $6.79 \pm .0 .20^{\mathrm{a}}$ & $6.14 \pm 0.31^{\mathrm{a}}$ & $<0.001$ \\
Lymphocyte & $68.66 \pm 2.02^{\mathrm{b}}$ & $78.33 \pm .2 .90^{\mathrm{a}}$ & $75.95 \pm 1.51^{\mathrm{a}} \mathrm{b}$ & 0.050 \\
Heterophil & $24.11 \pm 1.49^{\mathrm{a}}$ & $13.00 \pm 0.57^{\mathrm{c}}$ & $18.22 \pm 0.78^{\mathrm{b}}$ & 0.001 \\
H/L ratio & $0.35 \pm 0.03^{\mathrm{a}}$ & $0.16 \pm .0 .08^{\mathrm{c}}$ & $0.24 \pm 0.01^{\mathrm{b}}$ & 0.002 \\
\hline
\end{tabular}

a,b Data in the same row direction with different letters are differ significantly $(P<0.05)$ significantly $(P<0.05)$ using both kinds of probiotic supplementation compared to control treatment. The best result was recorded with $L$. animalis (PRO1) compared to the commercial multi probiotic (PRO2). While, no significant $(P>0.05)$ differences were observed among treatments on hemoglobin traits.

\section{DISCUSSION}

Nowadays, there are various production systems to improve poultry quality performance and health benefits one of them using probiotics that increase the products due to the recent ban of antibiotics. This study proved that the significant efficacy of dietary supplemented with probiotic $L$. animalis and commercial multi-bacteria probiotic on growth performance, cecal microbiota, and hematology of local quails. There are a different of beneficial microorganism species used as probiotics in poultry feed (Akoy, 2015; Mountzouris et al., 2010; Patterson and Burkholder, 2003; Khaksefidi and Rahimi, 2005). In general, beneficial bacteria that used in poultry feed belonging to the Bifidobacterium, Streptococcus, Bacillus, Lactobacillus, Enterococcus, Aspergillus, Candida, and Saccharomyces have a significant influence on broiler quality performance (Kalavathy et al., 2003; Zulkifli et al., 2000; Kabir et al., 2004; Gil De Los Santos et al., 2005), modification of small intestine microbiota, and suppress the harmful bacteria (Pascual et al., 1999).

The data of this research showed in Table 1 indicated that both types of probiotic administration were significantly $(P<0.05)$ improved body weight gain, feed conversion ratio and EPEF, this significant improvement in feed conversion ratio was showed by (Akoy, 2015; Zeweil, 1997; Chumpawadee et al., 2009; Devarestti, 2016; Mohammadreza et al., 2016). Probiotics are considered to encourage poultry performance and increase immune system, on the other hand, suppresses pathogen bacteria. The advantage of probiotic administration most important in poultry feed, not like antibiotics that kill all kind of bacteria and there is remain in the meats and eggs production that influence on the health of consumers. Today, probiotics are used strain-specific, live bacteria as probiotic cultures that produce a beneficial influence on the host. These microorganisms may be used such a single strain of bacteria or a group of many bacteria together, such us multi-strain beneficial bacteria all together, may have more influence on the health of poultry. These bacteria used as a probiotic generally isolated from the GIT of a healthy animal, then as probiotics will be applied to the diet of specific animals. Subsequently, these bacteria could become a portion of common microbiota in the small intestine, could be remained through GIT passage, and 
ability of bacteria as probiotic to adhere and colonize the small intestinal tract. The study by Harimurti and Kurniasih (2010) showed that indigenous lactic acid bacteria isolated from the GIT of healthy Indonesian native adult chickens (Ayam kampung), including Streptococcus thermophilus $\mathrm{Kd} 2$, Pediococcus acidilactici Kp6, and Lactobacillus murinus Ar3 showed significant effect as a feed additive to get better live growth performance of chickens.

This research showed the effect of dietary probiotic administration on the microbiota profile of the digesta of cecum as revealed by culture method in local quails. Counting of Lactobacillus spp. was increased by adding either L. animalis which was isolated from cecum of chicken or multi-strain commercial probiotics. The improvement of the numbering of Lactobacillus spp. and lower coliform bacteria detected in quails with both types of probiotics could be due to decreasing $\mathrm{pH}$ value in the small intestine and raise the production of SCFA (Fuller, 2001). Lactic acid bacteria strains are capable of converting carbohydrate substrates into organic acids (mainly lactic acid) and producing a wide range of metabolites that effect on some microorganisms in GIT. The homolactic and heterolactic species are produced lactic acid that decreases the $\mathrm{pH}$ value of the intestine content and increases the short-chain fatty acid, which is harmful to some kind of harmful bacteria. Furthermore, lactic acid bacteria are produced acetic acid and hydrogen peroxide that restrained against coliforms bacteria, Salmonella spp., and Clostridia spp. Largely, Lactobacillus spp. remedy is claimed to improve the growth performance of layer hens and broilers by killing the harmful bacteria and influence of E. coli in the GIT (Mudalgi et al., 1993; Kumprecht et al., 1994; Kapil et al., 2015).

The present study showed that no significant differences were observed between single strain and multi-strain probiotic supplementation as commercial probiotics. This result is in agreement with Mountzouris et al. (2010), who showed that the addition of probiotic (PoultryStar ME, Biomin GmbH, Herzogenburg Austria) in the feed of broilers increased the number of Lactobacillus spp. and Bifidobacterium spp. compared to control treatment. The research conducted by Smirnov et al. (2005) resulted that the use of probiotic ( $2 \mathrm{~g} / \mathrm{kg}$ of diet), including the live bacteria Bifidobacterium bifidum, L. acidopbilus, Lactobacillus casei, and Enterococcus faecium (minimum $1.0 \times 10^{8}$ $\mathrm{CFU} / \mathrm{g}$ ) increased positively the number of Lactobacillus spp. in the ileum part of small intestine by $147 \%$ compared to control treatment. Probiotic supplementation of the intestinal microbiota in poultry, particularly deal with Lactobacillus species, showed a beneficial influence on resistance to infection by some kind of harmful bacteria such as E. coli (Jin et al., 1996), Salmonella sp. (Pascual et al., 1999; Wali, 2012; Akoy, 2015), Campylobacter sp. (Stern et al., 2001), and, more recently, Eimeria acervulina (Dalloul et al., 2003).

\section{CONCLUSIONS}

The present study indicates that the L. animalis strain used as a probiotic had important influences on growth performance, gut microbiota, and hematology parameters of local quails. Furthermore, the commercial bacteria (multi-strain bacteria) showed significant improvement compared to the control treatment. Furthermore, there were no significant differences observed between both types of probiotics.

\section{REFERENCES}

Akoy, R. A. M. 2015. The Effects of Probiotics, Prebiotics and Synbiotics on Gut Flora, Immune Function and Blood Characteristics of Broilers. Ph. D. Thesis, Plymouth University, United Kingdom.

Anjum, M., A. Khan, A. Azim and M. Afzal. 2005. Effect of dietary supplementation of multi-strain probiotic on broiler growth performance. Pak. Vet. J. 25: 25-29.

Apata, D. F. 2008. Growth performance, nutrient digestibility and immune response of broiler chicks fed diets supplemented with a culture of Lactobacillus bulgaricus. J. Sci. Food Agric. 88: 1253-1258.

Baurhoo, B., L. Phillip and C. A. Ruiz-Feria. 2007. Effects of purified lignin and mannan oligosaccharides on intestinal integrity and microbial populations in the ceca and litter of broiler chickens. Poult. Sci. 86: 1070-1078.

Chumpawadee, S., A. Chantiratikul and S. Santaweesuk. 2009. Effect of dietary inclusion of cassava yeast as probiotic source on egg production and egg quality of laying hens. Int. J. Poult. Sci. 8: 195-199.

Dalloul, R. A., H. S. Lillehoj, T. A. Shellem and J. A. Doerr. 2003. Enhanced mucosal immunity against Eimeria acervulina in broilers fed a Lactobacillus-based probiotic. Poult. Sci. 82: 62-66.

Devarestti, A. K. 2016. Effect of dietary yeast on the performance and biochemical profile in Japanese quails. Int. J. Vet. Sci. Anim. Husbandry. 1(2): 27-29.

Duncan, D. B. 1995. Multiple range and multiple F test. Bometrics. 11: $1-42$.

Fuller, R. 2001. The chicken gut microflora and probiotic supplements. J. Poult. Sci. 38: 189-196.

Gil De Los Santos, J. R., O. B. Storch and C. Gil-Turnes. 2005. Bacillus cereus var. toyoii and Saccharomyces boulardii increased feed efficiency in broilers infected with Salmonella Enteritidis. Br. Poult. Sci. 46: 494-497.

Harimurti, S. and E. S. Kurniasih. 2010. Utilization of Indigenous Lactic Acid Bacteria Probiotics as a Substitute for Antibiotic in Broiler Chickens. Paper Presented at the $15^{\text {th }}$ World Congress of Food Science and Technology, Cape Town, South Africa. p22-26.

Jin, L. Z., Y. W. Ho, N. Abdullah and S. Jalaludin. 1997. Probiotics in poultry: Modes of action. Worlds Poult. Sci. J. 53: 351-368.

Jin, L. Z., Y. W. Ho, N. Abdullah and S. Jalaudin. 1996. Influence of dried Bacillus subtilis and lactobacilli cultures on intestinal microflora and performance in broilers. Asian Australas. J. Anim. Sci. 9: 99-107.

Kabir, S. M. L., M. M. Rahman, M. B. Rahman, M. M. Rahman and S. U. Ahmed. 2004. The dynamics of probiotics on growth performance and immune response in broilers. Int. J. Poult. Sci. 3: $361-364$. 
Kalavathy, R., N. Abdullah, S. Jalaludin. Y. W. Ho. 2003. Effects of Lactobacillus cultures on growth performance, abdominal fat deposition, serum lipids and weight of organs of broiler chickens. Br. Poult. Sci. 44: 139-144.

Kapil, J., K. S. Sharma, S. Katoch, V. K. Sharma and B. G. Mane. 2015. Probiotics in broiler poultry feeds: A review. J. Anim. Nutr. Physiol. 1: 4-16.

Khaksefidi, A. and S. Rahimi. 2005. Effect of probiotic inclusion in the diet of broiler chickens on performance, feed efficiency and carcass quality. Asian-Aust. J. Anim. Sci. 18(8): 1153-1156.

Khosravi, A., F. Boldaji, B. Dastar and S. Hasani. 2010. Immune response and performance of broiler chicks fed protexin and propionic acid. Int. J. Poult. Sci. 9: 188-191.

Kumprecht, I., P. Zobac, Z. Gasnarek and E. Robosova. 1994. The effect of continuous application of probiotics based on Saccharomyces cerevisiae var. Elipsoideus and Streptococcus faecium C-68 (SF-68) on chicken broilers yields. Zivocisna Viroba. 39(6): 491-503.

Li, L., Z. Hou, T. Li, G. Wu, R. Huang, Z. Tang, C. Yang, J. Gong, H. Yu and X. Kong. 2008. Effects of dietary probiotic supplementation on ileal digestibility of nutrients and growth performance in 1- to 42-day-old broilers. J. Sci. Food Agric. 88: 35-42.

Mehr, M., M. Shargh, B. Dastar, S. Hassani. and M. Akbari. 2007. Effect of different levels of protein and protexin on broiler performance. Int. J. Poult. Sci. 6: 573-577.

Mohammadreza, P., A. Seidavi, L. Asadpour and M. Andrés. 2016. Probiotic level effects on growth performance, carcass traits, blood parameters, cecal microbiota, and immune response of broilers. Ann. Braz. Acad. Sci. 88(2): 1011-1021.

Mountzouris, K. C., P. Tsitrsikos, I. Palamidi, A. Arvaniti, M. Mohnl, G. Schatzmayr and K. Fegeros. 2010. Effects of probiotic inclusion levels in broiler nutrition on growth performance, nutrient digestibility, plasma immunoglobulins, and cecal microflora composition. Poult. Sci. 89(1): 58-67.

Mountzouris, K., P. Tsitrsikos, E. Kalamara, S. Nitsch, G. Schatzmayr and K. Fegeros. 2007. Evaluation of the efficacy of a probiotic containing Lactobacillus, Bifidobacterium, Enterococcus, and Pediococcus strains in promoting broiler performance and modulating cecal microflora composition and metabolic activities. Poult. Sci. 86: 309-317.

Mudalgi, P., R. Sing and S. Verma. 1993. Effect of feeding probiotics on the performance of broilers. Indian J. Poult. Sci. 28(3): 195-199.

Murry, A. C., J. A. Hinton and R. J. Buhr. 2006. Effect of botanical probiotic containing lactobacilli on growth performance and populations of bacteria in the ceca, cloaca, and carcass rinse of broiler chickens. Int. J. Poult. Sci. 5: 344-350.

Nayebpor, M., P. Farhomand and A. Hashemi. 2007. Effects of different levels of direct fed microbial (Primalac) on growth performance and humoral immune response in broiler chickens. J. Anim. Vet. Adv. 6: 1308-1313.

Pascual, M., M. Hugas, J. I. Badiola, J. M. Monfort and M. Garriga. 1999. Lactobacillus salivarius CTC2197 prevents Salmonella enteritidis colonization in chickens. Appl. Environ. Microbiol. 65: 4981-4986.

Patterson, J. A. and K. M. Burkholder. 2003. Application of prebiotics and probiotics in poultry production. Poult. Sci. 82: 627-631.

Pelicano, E. R. L., P. A. Souza, H. B. A. Souza, D. F. Figueiredo, M. M. Boiago, S. R. Carvalho and V. F. Bordon. 2005. Intestinal mucosa development in broiler chickens fed natural growth promoters. Braz. J. Poult. Sci. 7(4): 221-229.

Ragione, R. M., A. Narbad, M. J. Gasson and M. J. Woodward. 2004. In vivo characterization of Lactobacillus johnsonii Fl9785 for use as a defined competitive exclusion agent against bacterial pathogens in poultry. J. Appl. Bacteriol. 38: 197-205.

Shim, Y. H., P. Shinde, J. Choi, J. Kim, D. K. Seo, J. Pak, B. Chae and I. Kwon. 2010. Evaluation of multimicrobial probiotics produced by submerged liquid and solid substrate fermentation methods in broilers. Asian Aust. J. Anim. Sci. 23: 521-529.

Smirnov, A., R. Perez, E. Amit-Romach, D. Sklan and Z. Uni. 2005. Mucin dynamics and microbial population in chicken small intestine are changed by dietary probiotic and antibiotic growth promoter supplementation. J. Nutr. 13: 187-192.

Stern, N. J., N. A. Cox, J. S. Bailey, M. E. Berrang and M. T. Musgrove. 2001. Comparison of mucosal competitive exclusion and competitive exclusion treatment to reduce Salmonella and Campylobacter spp. colonization in broiler chickens. Poult. Sci. 80: 156-160.

Wali, N. 2012. The effects of Lactobacillus plantarum NCIMB 41607 on Salmonella Infection and the Microbial Population in the Gastrointestinal Tract of the Chicken. Master Thesis. Plymouth University, England.

Wang, Y. and Q. Gu. 2010. Effect of probiotic on growth performance and digestive enzyme activity of Arbor Acres broilers. Res. Vet. Sci. 89: 163-167.

Zakeri, A. and P. Kashefi. 2011. The comparative effects of five growth promoters on broiler chickens humoral immunity and performance. J. Anim. Vet. Adv. 10: 1097-1101.

Zeweil, H. S. 1997. Evaluation of using some feed additives in growing Japanese quail diets. J. Agric. Sci. 11: 3611-3622.

Zulkifli, I., N. Abdullah, N. M. Azrin and Y. W. Ho. 2000. Growth performance and immune response of two commercial broiler strains fed diets containing Lactobacillus cultures and oxytetracycline under heat stress conditions. Br. Poult. Sci. 41: 593-597. 